\title{
Физическая подготовленность девушек-студенток Северо-восточного государственного университета в период обучения в вузе
}

\author{
Зайщева Н.В., Кудлова Е.Е. *, Аверъянова И.В. \\ Северо-восточный государственный университет \\ г. Магадан, Россия \\ ORCID: 00OO-OOO2-8012-5027,nin_angel@mail.ru \\ ORCID: 0ooo-0002-6857-6861, eelubimtseva@gmail.com* \\ ORCID: oooo-0oo2-4511-6782, Inessa1382@mail.ru
}

\begin{abstract}
Аннотация: Приведены результаты 4-летнего мониторинга за уровнем физической подготовленностью 1110 девушек-студенток Северо-Восточного Государственного университета в процессе обучения в ВУЗе в возрасте 17-21 года. Полученные результаты указывают на то, что уровень физической подготовленности девушек-студенток СВГУ не имел значительных отличий от показателей сверстниц из других регионов страны, а зачастую превышал их. Положительная динамика физической подготовленности в период обучения в ВУЗе регистрировалась относительно 2 анализируемых тестов из 6 («Наклоны вперед из положения сидя» и «Прыжки на скакалке»). При этом отрицательная динамика была зафиксирована относительно следующих показателей: «Прыжок в длину с места», «Сгибание и разгибание рук в упоре». Установлен разнонаправленный характер динамики относительно тестов ««Поднимание туловища из положения лежа на спине» и «Челночный бег» с наивысшими показателями на 3-м курсе и снижением к 4-му курсу обучения. В целом, у студенток всех курсов обучения наиболее низкий показатель оказался в тесте «прыжок в длину с места», остальные нормативы выполнялись на 4 и 5 баллов. Выявленные особенности уровня физической подготовленности студенток СевероВосточного Государственного университета необходимо учитывать при планировании и организации учебных занятий по физической культуре.
\end{abstract}

Ключевые слова: девушки-студентки, тестирование физических качеств, уровень физической подготовленности.

Для цитирования: Зайцева Н.В., Кудлова Е.Е.*, Аверьянова И.В. Физическая подготовленность девушек-студенток Северо-Восточного государственного университета в период обучения в вузе. Педагогико-психологические и медико-биологические проблемы физической культуры и спорта. 2020; 15(4): 38-43. DOI: 10.14526/2070-4798-2020-15-4-38-43

\section{Physical training of female students at North-Eastern State University during the period of studying at a higher educational establishment}

\author{
Nina V. Zaytseva, Ekaterina E. Kudlova*, Inessa V. Averyanova \\ North-Eastern State University \\ Magadan, Russia \\ ORCID: oooo-ooo2-8012-5027,nin_angel@mail.ru \\ ORCID: 00oo-0002-6857-6861, eelubimtseva@gmail.com* \\ ORCID: 00oo-0oo2-4511-6782, Inessa1382@mail.ru
}

\begin{abstract}
Physical training is an important index of a person's health state, close connection between them was observed by the scientists long ago. Nowadays there is physical health state level decrease in students in Russian regions. It is connected with unfavorable ecological situation, social-economic conditions of life, bad habits, sedentary life style, genetically conditioned factors and etc. Every year, as the practice shows, we observe the increase of students, who study in special medical groups. About 90\% of young people have health problems and more than 50\% have insufficient physical fitness. Materials. Physical readiness monitoring in order to get information for physical upbringing control and its quality improvement. Research methods. Information sources analysis and summarizing, female students' physical readiness analysis, testing, methods of mathematical statistics. Results. We present the results of 4-year monitoring
\end{abstract}


of physical readiness level in 1110 female students from North-Eastern State University (NESU) during their studying at the age of 17-21. The received results show that the level of physical readiness in female students of NESU didn't have considerable differences from the indices of their coevals from other regions of the country and in some cases exceeded them. Positive dynamics of physical readiness during their study at the University was registered relative to two analyzed tests from 6 ("Lean forward from sitting position" and "Skipping"). At the same time, negative dynamics was registered in the following indices: "Standing long-jump", "Dip up". We registered multidirectional character of the dynamics relative to the following tests: "Body lifting from dorsal position" and "Shuttle run" with the highest indices at the $3^{\text {rd }}$ course and the decrease by the $4^{\text {th }}$ course of study. Female students of all courses of study had a low index in "Standing long-jump" test, other normatives were fulfilled for 4 and 5 points. Conclusion. The revealed peculiarities of physical readiness level in female students at NESU should be taken into account during physical culture lessons planning and organization.

Keywords: female students, physical qualities testing, physical readiness level.

For citation: Nina V. Zaytseva, Ekaterina E. Kudlova*, Inessa V. Averyanova. Physical training of female students at North-Eastern State University during the period of studying at a higher educational establishment. Russian Journal of Physical Education and Sport. 2020; 15(4): 38-43. DOI: 10.14526/20704798-2020-15-4-38-43

\section{ВВЕДЕНИЕ}

Физическая подготовленность является важным показателем состояния здоровья человека, тесную взаимосвязь между которыми ученые наблюдали давно. Целью мониторинга физической подготовленности является получение информации, необходимой для совершенствования управления процессом физического воспитания, и таким образом, улучшение его качества. К числу основных кондиционных физических качеств, по которым осуществлялся мониторинг, можно отнести быстроту, выносливость, силу [1]. В настоящее время в российских регионах происходит снижение уровня физического здоровья студенческой молодежи [2]. Это связано с неблагоприятной экологической ситуацией, социально-экономическими условиями жизни населения, вредными привычками, малоподвижным образом жизни, генетически обусловленными факторами и т.д. [3]. С каждым годом, как свидетельствует практика, увеличивается количество студентов, занимающихся в специальных медицинских группах. Около 90\% молодежи имеют отклонения в состоянии здоровья, а более 50\% - недостаточную физическую подготовленность [4].

\begin{tabular}{lcr}
\multicolumn{1}{c}{ Ранее } & нами & рассматривались \\
особенности & физической & подготовленности \\
организма & юношей-студентов & Северо-
\end{tabular}

восточного Государственного университета [5] тогда как среди девушек-студенток аналогичных исследований не проводилось.

Исходя их чего, целью наших исследований явилось изучение динамики основных показателей физической подготовленности у девушек-студенток СевероВосточного Государственного университета с 1-го по 4-й курс обучения.

\section{МАТЕРИАЛ И МЕТОДЫ}

Для поставленной цели в период с 2004 по 2019 годы нами было проведено исследование физической подготовленности студенток Северо-восточного государственного университета. В исследовании участвовало 1110 девушек: 17 лет (1 курс) - 270 девушек, 18 лет (2 курс) - 370 студенток, 19 лет (3 курс) - 270 девушек , 20 лет (4 курс) - 200 девушек.

Анализ физической подготовленности студенток СВГУ был проведен по следующим показателям: прыжок в длину с места толчком двумя ногами (см), сгибание и разгибание рук в упоре лежа на полу (количество, раз), поднимание туловища из положения лежа на спине (количество, раз), наклоны вперед из положения сидя с прямыми ногами (от уровня пяток - см), челночный бег 4 *15 м (сек), прыжки на скакалке на двух ногах за 1 мин (количество, раз), бег 100 м (сек). Оценивание физической подготовленности проводилось в соответствии с 
фондом оценочных средств рабочей программы спорту» (табл. 1). «Элективные курсы по физической культуре и

Таблица 1 - Контрольные нормативы для оценки физической подготовленности студенток

\begin{tabular}{|c|c|c|c|c|c|c|}
\hline \multirow{2}{*}{$\begin{array}{c}\mathrm{N} \\
\Pi / \Pi\end{array}$} & \multirow{2}{*}{$\begin{array}{c}\text { УПРАЖНЕНИЯ } \\
\text { (нормативы) }\end{array}$} & \multicolumn{5}{|c|}{ Оценка в баллах } \\
\hline & & 5 & 4 & 3 & 2 & 1 \\
\hline 1. & $\begin{array}{c}\text { Прыжок в длину с места толчком двумя } \\
\text { ногами (см) }\end{array}$ & 190 & 180 & 168 & 160 & 150 \\
\hline 2. & $\begin{array}{c}\text { Поднимание туловища из положения лежа на } \\
\text { спине (количество, раз) }\end{array}$ & 60 & 55 & 50 & 45 & 40 \\
\hline 3. & $\begin{array}{c}\text { Сгибание и разгибание рук в упоре лежа на } \\
\text { полу (количество, раз) }\end{array}$ & 20 & 17 & 14 & 10 & 7 \\
\hline 4. & $\begin{array}{l}\text { Прыжки на скакалке на двух ногах за } 1 \text { мин } \\
\text { (количество, раз) }\end{array}$ & 140 & 130 & 120 & 110 & 100 \\
\hline 5. & Челночный бег 4X15м (сек) & 16.0 & 16.6 & 17.2 & 18.0 & 18.8 \\
\hline 6. & $\begin{array}{c}\text { Наклоны вперед из положения сидя с } \\
\text { прямыми ногами (от уровня пяток - см) }\end{array}$ & 18 & 15 & 12 & 9 & 5 \\
\hline
\end{tabular}

\section{РЕЗУЛЬТАТЫ И ОБСУЖДЕНИЕ}

В таблице 2 представлены результаты физической подготовленности девушекстуденток г. Магадана за период обучения в ВУЗе. Полученные данные указывают на то, что, результаты теста на динамическую силу мышц нижних конечностей - «прыжок в длину с места» имели отрицательную динамику к 4 курсу обучения и во все периоды исследования соответствовали оценке «удовлетворительно». Но при этом необходимо указать на то, что средние величины данного показателя, полученные в нашем исследовании несколько превышают результаты тестов девушекстуденток Адыгейского государственного университета (г. Майкоп) у которых показатель прыжка в длину составил 157,8土21,1 см [6], и девушек Прибайкалья у которых средние значения прыжка в длину с места были равны $159,6 \pm 6,6$ см [7] и студенток Южно-Уральского государственный университета (Челябинск) ( (166 4 4,62 cм) [8] и не отличались от результатов студенток УлГПУ им. И.Н. Ульянова [9] и института естественных и технических наук Сургутского государственного университета [10] где результаты составили 173,21 $\pm 2,5$ см и 173,2 см соответственно.

Характеристика скоростно-силовой выносливости мышц сгибателей туловища «подъем туловища из положения лежа» соответствовала оценке «хорошо» во всех периодах исследования, но при этом наилучший результат был характерен девушкам 3-го курса с тенденцией снижения на последнем курсе обучения. Полученные в наших исследованиях результаты у девушек-студенток оказались несколько выше, чем у обследуемых института естественных и технических наук Сургутского государственного университета $(49,9)$ [10,11,12,13,14], у студенток технического ВУЗа Прибайкалья $(49,02 \pm 0,4$ раз) [7] и Студенток Южно-Уральский государственного университета (Челябинск) (51.6 $\pm 2 ., 30$ раз) [8].

Развитие гибкости девушек, которое определялось путем выполнения наклона вперед из положения сидя на гимнастической скамейке соответствовало оценке «хорошо» во все периоды исследования. При этом необходимо указать на наличие положительной в период обучения в вузе ввиду развития гибкости достигнутого самого высокого показателя к 4-му курсу обучения.

Физическая подготовленность у девушек при выполнении физического упражнения «сгибание и разгибаниерук вупорележа на полу» соответствовала оценке «хорошо», при этом девушки - старшекурсницы характеризовались статистически значимо более низкими показателями относительно девушек 1-го и 2-го курса.

Результаты испытания, направленного на оценку выносливости, а также прыгучести и координационных способностей, которые анализировались на основе теста «Прыжки на 
скакалке на двух ногах» у девушек 1-го курса составили 132,22 $\pm 1,23$ раз, что соответствует 3 баллам, для девушек 2- го курса данная величина была равна $136,73 \pm 1,08$ раз, что соответствовало 4 баллам, а для девушек-старшекурсниц (3-й и 4-й курсы) выполнение данного упражнения соответствовало оценке «отлично» и оставило $139,74 \pm 1,23$ и 138,77 $\pm 1,49$ раз.

В тесте на скоростную выносливость и ловкость («Челночный бег») была отмечена положительная динамика в процессе обучения с наилучшими величинами у обследуемых 3-го курса и с наихудшими у представительниц первого курса.

\section{ЗАКЛЮЧЕНИЕ}

Таким образом, полученные результаты указывают на то, что уровень физической подготовленности девушек-студенток СВГУ не имел значительных отличий от показателей сверстниц из других регионов страны, а зачастую превышал их. При этом результаты мониторингового наблюдения за показателями физической подготовленностью студенток СВГУ показали, что улучшения в период обучения в ВУЗе произошли в таких тестах как «Наклонь вперед из положения сидя» и «Прыжки на скакалке». При этом отрицательная динамика была зафиксирована относительно следующих показателей: «Прыжок в длину с места», «Сгибание и разгибание рук в упоре». Результаты динамики по тестам «Поднимание туловища из положения лежа на спине» и «Челночный бег» характеризовались разнонаправленным характером, что проявлялось улучшением их выполнения на 3-м курсе и снижением к 4-му курсу обучения. При этом сопоставляя полученные результаты с требованиями программы дисциплины «Физическая культура» средние значения по полученным тестам имели следующую балльную оценку: «Прыжок в длину» на всех курсах обучения соответствовал оценке в 3 балла, «Сгибание и разгибание рук в упоре лежа на полу», «Поднимание туловища из положения лежа на спине», «Наклоны вперед из положения сидя с прямыми ногами» на всех курсах обучения был равен оценке в 4 балла, результаты теста «Прыжки на скакалке на двух ногах» на 1-м и 2-м курсах соответствовал оценке «хорошо», а на 3-м и 4-м курсах - «отлично» и испытание «Челночный бег» на 1-м курсе характеризовался оценкой «удовлетворительно», на 2-м и 4-м курсе оценкой «хорошо» и на 3-м курсе соответствовал 5-ти баллам. Полученные данные указывают на то, что физическая подготовленность студенток по большему числу тестов соответствует нормативным требованиям, при этом у девушек курсов обучения наиболее низкий показатель оказался в тесте «прыжок в длину с места».

\section{СПИСОК ЛИТЕРАТУРЫ}

1. Юречко О.В. Физическое развитие и физическая подготовленность в системе мониторинга состояния физического здоровья школьников. Фундаментальные исследования. 2012; 3: 324-327.

2. Шаратских А.Ю., Кузекевич В.Р. Сравнительный анализ уровня физической подготовленности студентов первых курсов педагогического института ИГУ. Ученые записки университета имени П.Ф. Лесгафта. 2016; 4(134): 298-306.

3. Яцун C.M., Беспалов Д.В., Горбунова А.С. Мониторинг состояния здоровья и физического развития студентов КГУ и реализация его результатов в электронном «Паспорте здоровья». Здоровъе для всех. 2016; 1: 3-7.

4. Бакурідзе В.Б. Результати дослідження зацікавленості студентської молоді до занять культурою і спортом. Педагогіка, психологія та медико-біологічні проблеми фізичного виховання $i$ спорту: Зб.наук.пр. 2002; 3: 52-56.

5. Аверьянова И.В., Зайцева H.В. Региональные особенности морфофизиологических характеристик и физической подготовленности студентов СевероВосточного государственного университета. Человек. Спорт. Медицина. 2018; 18(3): 60-68

6. Чермит К.Д., Заболотний А.Г., Цеева Н.А., Мирза М.Ю., Вержбицкая Е.Г. Оценка физической подготовленности студентов высшихучебных заведений на основетребований всероссийского физкультурно-спортивного комплекса «ГТО» (готов к труду и обороне). Вестник Адыгейского государственного университета. 2018; 4(211): 104-108.

7. Колокольцев М.М., Амбарцумян Р.А. Сравнительная характеристика физического развития и физической подготовленности студенток технического вуза Прибайкалья в 
условиях поликультурной образовательной среды. Вестник ИрГТУ. 2013; 10 (81): 399-403.

8. Ушаков А.С., Ненашева А.В., Клещенкова Н.Е. Сравнительный анализ показателей физической подготовленности учащихся 11-х классов и студентов 1-го курса обучения. Вестник ЮУрГУ. Серия «Образование, здравоохранение, физическая культура». 2014; 2: 114-118.

9. Тимошина И.Н., Богатова С.В. Исследование динамики физической подготовленности студентов педагогических и непедагогических специальностей. Педагогикопсихологические и медико-биологические проблемы физической культуры и спорта. 2015; 1: 146-153

10. Бушева Ж.И., Беспалов Ю.Г., Ставрук М.А. Показатели физической подготовленности девушек института естественных и технических наук СурГУ. Сборник материалов XVII Всероссийской научно-практической конференции с международным участием. 2018: 343-346.

11. Ненашева А. В., Клещенкова Н. Е. Сравнительный анализ показателей физической подготовленности учащихся 11-х классов и студентов 1-го курса обучения. Вестник ЮУрГУ. Серия «Образование, здравоохранение, физическая культура». 2014; 14(2): 114-118.

12. Armstrong N., Welsman J.R. The physical activity patterns of European youth with reference to methods of assessment. Sport Medicine. 2006; 36: 147-159.

13. Craig C.L., Marshall A.L., Sjostrom M., Bauman A.E., Booth M.L., Ainsworth B.E., et al. International physical activity questionnaire: 12-country reliability and validity. Medicine and Sciences in Sports and Exercise. 2003; 35: 13811395 .

14. Esculcas C., Mota J. Physical activity and leisure behaviors and adolescents: The influence of physical activity characteristics and the socio-economic status. International Journal of Behavioral Medicine. 2000; 7: 208-213.

\section{Статья поступила в редакцию: 20.10.2020}

Зайцева Нина Валеръевна - стариий преподаватель, Северо-Восточный государственный университет, 685ооо, Россия, г. Магадан, ул. Портовая, дом 13, e-mail: nin angel@mail.ru

Кудлова Екатерина Евгенвевна - стариий преподаватель, Северо-Восточный государственный университет, 6850оо, Россия, г. Магадан, ул. Портовая, дом 13, e-таil: eelubimtseva@gmail.com

Аверъянова Инесса Владиславовна - кандидат биологических наук, доцент Северовосточного государственного университета, 685ооо, Россия, г. Магадан, ул. Портовая, дом 13, e-mail: inessa1382@mail.ru 


\begin{tabular}{|c|c|c|c|c|c|c|c|}
\hline \multirow{6}{*}{ 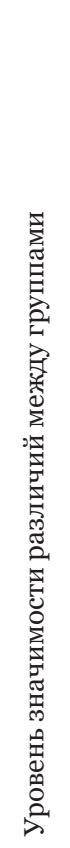 } & I & $\begin{array}{l}\stackrel{L}{0} \\
\dot{v} \\
\stackrel{v}{a}\end{array}$ & $\begin{array}{l}\stackrel{0}{0} \\
\dot{v} \\
\stackrel{v}{a}\end{array}$ & 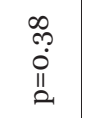 & $\begin{array}{l}\overrightarrow{0} \\
\dot{\dot{v}} \\
\text { un }\end{array}$ & $\begin{array}{l}\tilde{o} \\
\dot{0} \\
\dot{v} \\
\text { on }\end{array}$ & $\begin{array}{l}\tilde{a} \\
\dot{i} \\
\ddot{\alpha}\end{array}$ \\
\hline & $\stackrel{+}{d}$ & $\begin{array}{l}7 \\
0 \\
0 \\
\text { II. }\end{array}$ & $\begin{array}{l}\overrightarrow{0} \\
\dot{0} \\
\dot{v} \\
\text { val }\end{array}$ & 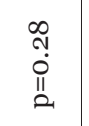 & $\begin{array}{l}\stackrel{q}{+} \\
0 \\
\stackrel{0}{\|} \\
2\end{array}$ & 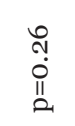 & 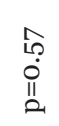 \\
\hline & $\stackrel{\mathscr{I}}{\sim}$ & 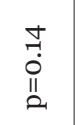 & $\begin{array}{l}\stackrel{0}{0} \\
\dot{0} \\
\stackrel{\|}{0}\end{array}$ & $\begin{array}{l}\overrightarrow{0} \\
\dot{\dot{v}} \\
\ddot{v}\end{array}$ & $\begin{array}{l}7 \\
\text { f } \\
0 \\
\text { II }\end{array}$ & $\begin{array}{l}\overrightarrow{0} \\
\dot{0} \\
\dot{0} \\
\text { on }\end{array}$ & $\begin{array}{l}\hat{0} \\
\dot{0} \\
\|_{1}\end{array}$ \\
\hline & 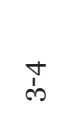 & $\begin{array}{l}\vec{y} \\
\dot{0} \\
\stackrel{\|}{a}\end{array}$ & $\begin{array}{l}\infty \\
0 \\
\dot{0} \\
\ddot{\|} \\
0 .\end{array}$ & $\begin{array}{l}\stackrel{0}{0} \\
\dot{0} \\
\stackrel{1}{2}\end{array}$ & $\begin{array}{l}\qquad 0 \\
0 \\
\dot{v} \\
\stackrel{v}{2}\end{array}$ & 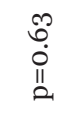 & 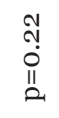 \\
\hline & $\stackrel{\sim}{\sim}$ & $\begin{array}{l}\text { ले } \\
\text { II } \\
\text { In }\end{array}$ & $\begin{array}{l}\hat{0} \\
\dot{0} \\
\text { II } \\
\text {. }\end{array}$ & 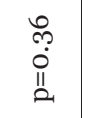 & $\begin{array}{l}\bar{m} \\
\stackrel{0}{\|} \\
\stackrel{\|}{\alpha}\end{array}$ & $\begin{array}{l}o \\
0 \\
\dot{0} \\
11 \\
2\end{array}$ & $\begin{array}{l}\text { चै } \\
\stackrel{0}{0} \\
\stackrel{1}{0}\end{array}$ \\
\hline & I & $\begin{array}{l}\text { fे } \\
\text { on } \\
\text { In }\end{array}$ & $\begin{array}{l}\stackrel{\vartheta}{a} \\
\stackrel{0}{\|}\end{array}$ & 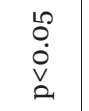 & $\begin{array}{l}\stackrel{N}{7} \\
\stackrel{0}{0} \\
\stackrel{11}{2}\end{array}$ & $\begin{array}{l}\overrightarrow{0} \\
\dot{\vec{v}} \\
\stackrel{v}{0}\end{array}$ & $\begin{array}{l}\text { \& } \\
\stackrel{1}{0} \\
\text { II } \\
\text { 2. }\end{array}$ \\
\hline \multirow{4}{*}{ 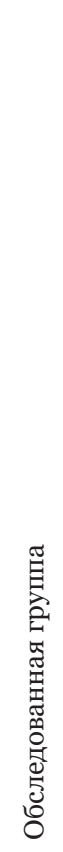 } & 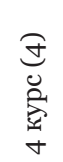 & $\begin{array}{l}\hat{\omega} \\
\hat{+} \\
\hat{H} \\
\sigma \\
\hat{\hat{\sigma}} \\
\hat{\sigma}\end{array}$ & $\begin{array}{l}\infty \\
0 \\
0 \\
0 \\
\ddot{0} \\
y \\
\hat{A}\end{array}$ & $\begin{array}{l}\infty \\
\infty \\
0 \\
01 \\
\hat{N} \\
\hat{N} \\
i n\end{array}$ & 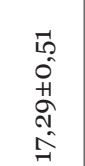 & 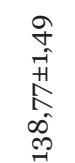 & 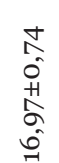 \\
\hline & 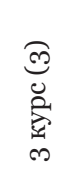 & 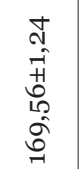 & $\begin{array}{l}\vec{m} \\
0 \\
\text { 苦 } \\
m \\
\infty \\
\sigma^{2}\end{array}$ & $\begin{array}{l}\vec{b} \\
0 \\
0 \\
0 \\
0 \\
i \hat{0} \\
i n م\end{array}$ & $\begin{array}{l}\text { t. } \\
0 \\
0 \\
+1 \\
0 \\
0 \\
0 \\
0\end{array}$ & 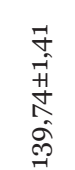 & $\begin{array}{l}1 \\
0 \\
0 \\
+1 \\
0 \\
0 \\
0 \\
0\end{array}$ \\
\hline & 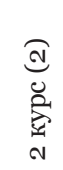 & $\begin{array}{l}0 \\
0 \\
0 \\
0 \\
0 \\
0 \\
\hat{0}\end{array}$ & 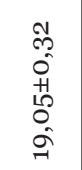 & 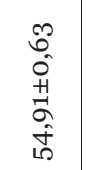 & 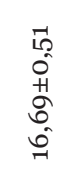 & $\begin{array}{l}\infty \\
0 \\
\hat{+} \\
0 \\
\hat{0} \\
\hat{0} \\
-0\end{array}$ & \begin{tabular}{l} 
చn \\
0 \\
0 \\
+1 \\
\multirow{1}{+}{} \\
0 \\
0
\end{tabular} \\
\hline & 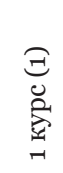 & 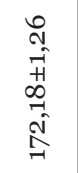 & 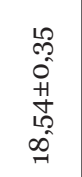 & 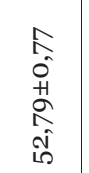 & 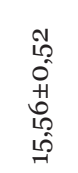 & 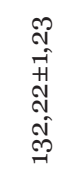 & $\begin{array}{l}\text { 10 } \\
0 \\
0 \\
0 \\
0 \\
0 \\
\hat{n}\end{array}$ \\
\hline \multicolumn{2}{|c|}{ 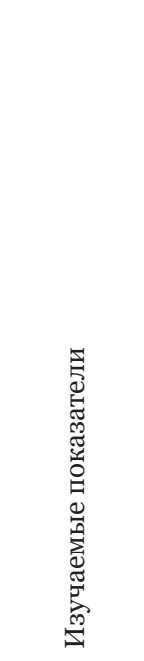 } & 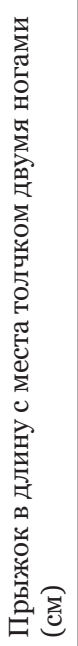 & 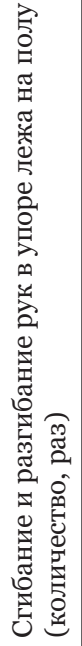 & 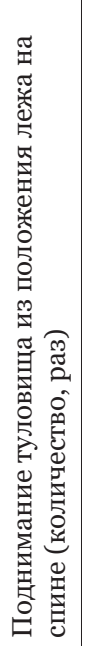 & 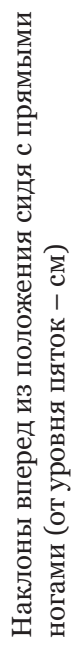 & 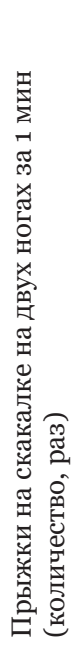 & 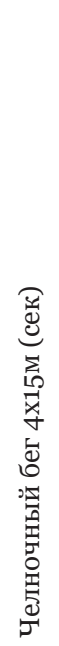 \\
\hline
\end{tabular}

